\title{
Research on the Assembly Process of Spindle System of Precision Lathe
}

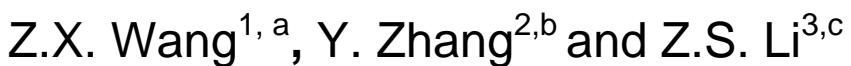 \\ ${ }^{1}$ Kunming university of science and technology, Kunming, Yunnan, China \\ ${ }^{2}$ Kunming university of science and technology, Kunming, Yunnan, China \\ ${ }^{3}$ Kunming Machine Tool, Kunming, Yunnan, China \\ a272346926@qq.com
}

Keywords: pindle system,precision lathe,assembly process,assembly accuracy

Abstract: The spindle system of precision lathe is one of the main parts of CNC lathe, and also a executive part of the main motion of the machine tool, it directly clamping the work piece and drive it to rotate.And the running accuracy directly relate to assembly accuracy.Through the corresponding assembly process experiment, the assembly process of precision spindle system is established, which ensures the assembly accuracy of the spindle system, improves the assembly quality and shortens the assembly cycle.

\section{Introduction}

The spindle components of precision lathe should not only be satisfied the requirements of high machining accuracy, but also have the ability to withstand the cutting force, and ensure a high rotation accuracy, and the accuracy of the rotation directly relate to assembly accuracy,if improper assembly,even though precision of all the parts are qualified, may not be able to assemble qualified components of the spindle system.

By analyzing the above problems and according to the requirements of the state of high precision CNC boring and milling machine development, a machine tool manufacturing enterprise and several universities have got together to take over the project named "high-end CNC machine tools and basic manufacturing equipment" ,which is the state plan for development of the basic research in key areas. The project has developed a high level of the world's models for THM46100 and THM65160 and other precision horizontal boring and milling machine.

In in the production practice of the project, according to the above phenomenon, in this paper, the process of spindle assembly were studied, and with the engineers from the machine tool manufacturing enterprise we have made spindle assembly task guidance documents, and have put forward the specific assembly requirements. Hope in the successful completion of the national key special at the same time, but also for the enterprise in the future of the spindle assembly process to ensure the spindle assembly quality, to reduce the error, improve work efficiency, shorten the assembly cycle.

\section{Study on assembly process of spindle system}

Spindle unit is the core component of the machine tool, the precision and the speed demand is high. Through the assembly and the corresponding process research experiments, the main components of the spindle system assembly process specification, to ensure the assembly accuracy of the spindle assembly, in order to improve the assembly quality, shorten the assembly cycle. The following will take the HM1 spindle as an example, we have studied the precision lathe spindle assembly process. 


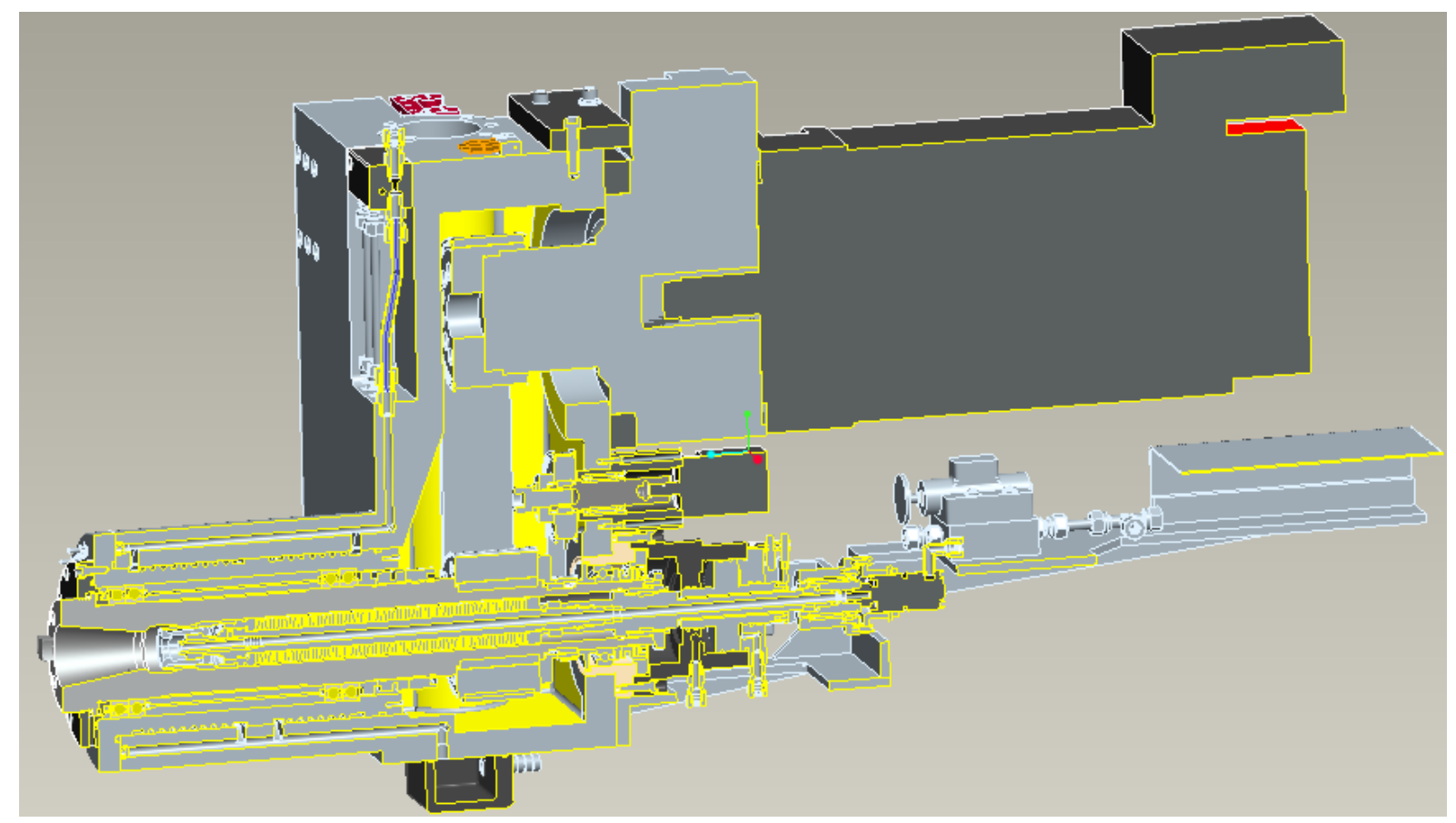

Figure1: Spindle system component diagram

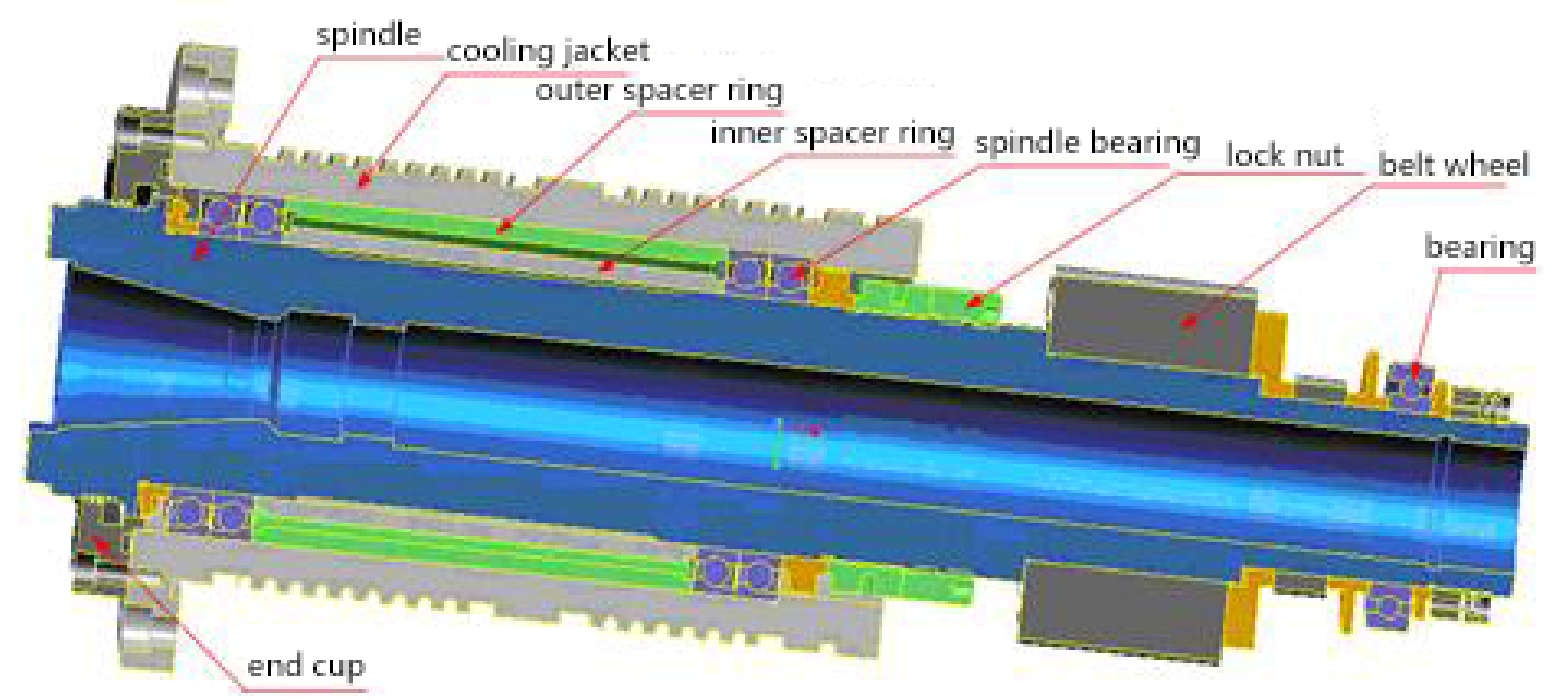

Figure2:Spindle component diagram

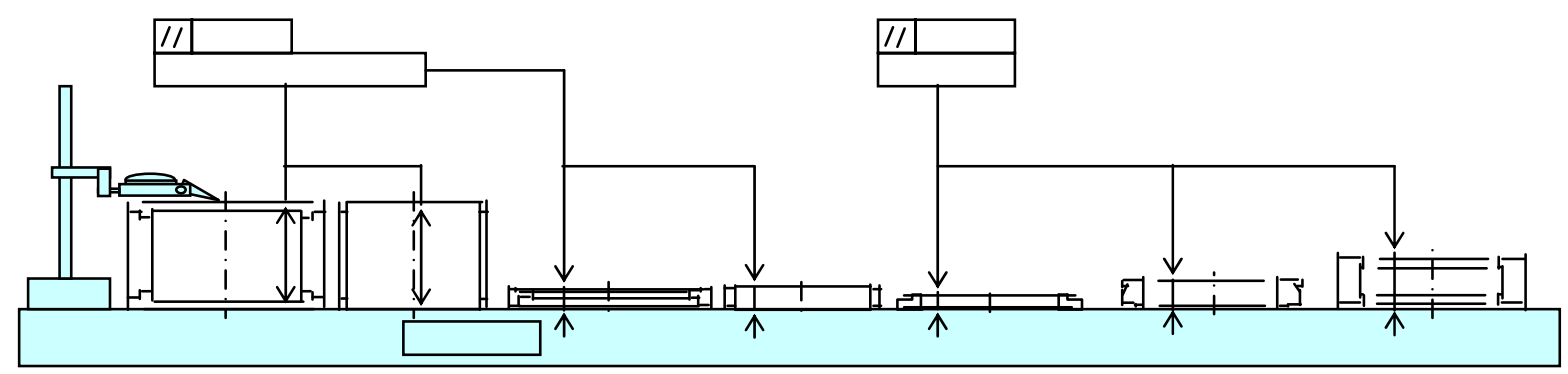

Figure3:Schematic diagram of parallelism measurement

\subsection{Preparation work}

1) From the warehouse to collect the necessary parts of the assembly, including homemade and purchased. 
a) Repair the burr of the self-made parts,then chamfer and clean them.

b) Check oil holes and air holes to ensure they are not blocked.

2) According to the number to the warehouse to receive the main shaft, sealing angular contact ball bearings ( 1 pieces of 4 sets), cooling jacket, a pair of locking nut, and install them.

3) Install inner spacer ring and outer ring according to number.

4) Install spindle pull claws by number.

5) Sent the butterfly spring to physical and chemical room by loose broach state pressure test, and according to assembly overlay on leaf spring, a group consisting of 3 pieces,and measuring the length of butterfly spring in loose broach state.

6) Repair the flat key between the belt wheel and the main shaft, and ensure that there is no loose phenomenon when it is repaired

\subsection{Spindle system component assembly}

1) Spindle assembly state: in the vertical state to carry out the spindle assembly work to ensure the high accuracy of the spindle requirements.

2) Measuring the parallel degree of the labyrinth and the spacer, the inner and outer ring, the requirement is less than $0.002 \mathrm{~mm}$. At the same time confirm the inner and outer spacer size is consistent, and there is no more than the requirements.

3) Install the left parts of the spindle. In order to install labyrinth, sleeve, angular contact ball bearings (pairs), inside and outside the ring, angular contact ball bearings (pairs), spacer sleeve, paired lock nut. And tighten the lock nut, pressing bearing, and ensure no axial movement of the bearing.

a) The spindle bearing is heated to a temperature less than $60^{\circ} \mathrm{C}$ by bearing heater,and heating according to the code of the bearing heater.

b) Preload of the blocking nut on the spindle bearing:Using torque wrench, according to the design requirements to 2 times the torque fastening.

4) First, the components of the front end of the spindle are placed vertically, then combine them with the cooling jacket.

5) Install the rear end parts of the spindle. The belt wheel, the spacer ring, the belt wheel, the spacer ring, the rear end bearing, the spacer ring and the locking nut are respectively arranged in the sequence. Finally, the bearing is pressed to ensure that the bearing has no axial movement.

6) The spindle assembly is assembled according to the dynamic balance diagram, and then enters the dynamic balance experiment,the accuracy level of the requirements within the G1.

7) The precision machining of the taper hole of spindle.With the bearing as the center of rotation,grinding the 7:24 taper to the size by the universal precision grinding machine, and make the conical contact $90 \%$, the spindle taper hole of the proximal beating at 0.001 , distal $300 \mathrm{~mm}$ in 0.003 .

8) The precision machining of the excircle of cooling sleeve.

9) Clean the exposed parts of the Spindle unit.

\subsection{Testing}

1) Using a broach force dynamometer test spindle loose broach whether meets the design requirements of assembly.

2) Geometric precision detection of the taper hole of spindle.

\subsection{Free running experiment of spindle system components}

In order to ensure the reliable operation of the spindle, we should run the test at different speeds after spindle assembly, and at the same time to detect the temperature rise and the operation of the spindle and the spindle of the relevant accuracy. 
1) While the spindle in high-speed operation, the temperature reached a balance, the maximum temperature shall not exceed $48^{\circ} \mathrm{C}$, temperature rise shall not exceed $28^{\circ} \mathrm{C}$.

2) Spindle box with the highest speed $* * * \mathrm{r} / \mathrm{min}$ rotation, noise sound pressure level shall not be greater than $78 \mathrm{~dB}(\mathrm{~A})$.

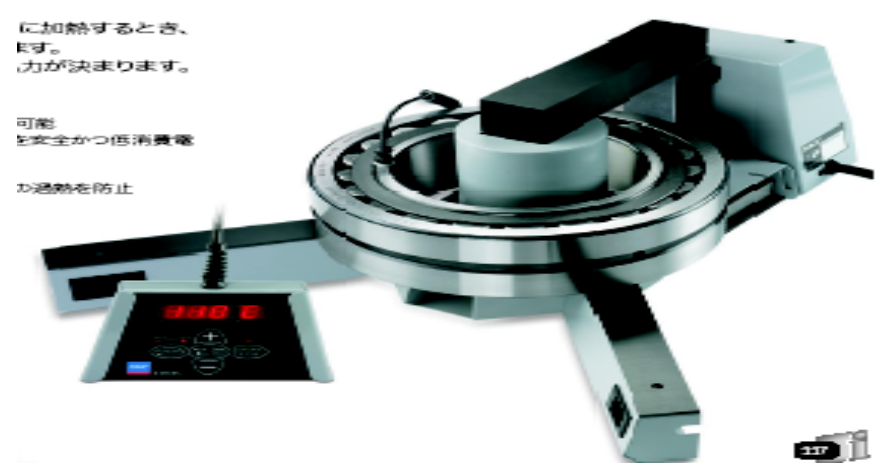

Figure4:Bearing heater

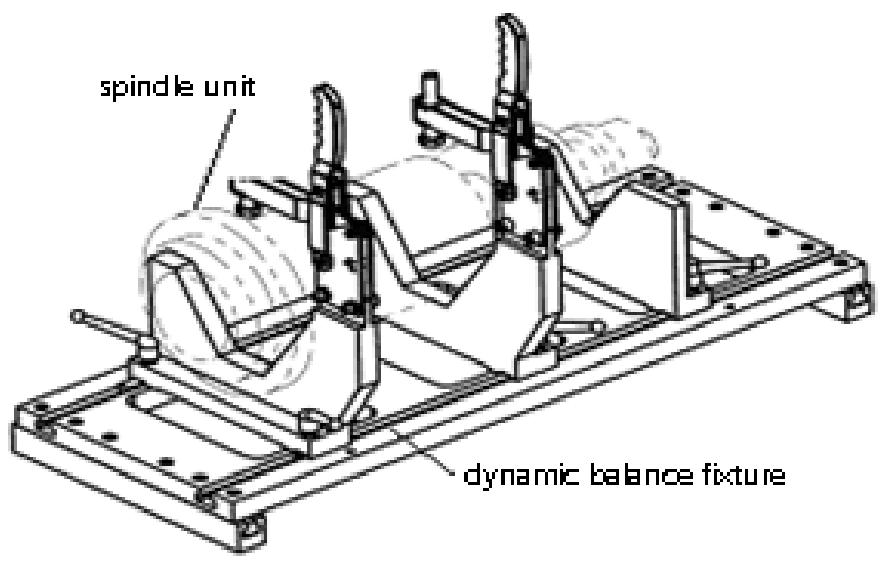

Figure5:Dynamic balance diagram of spindle component

\section{Conclusion}

The design of machine tool spindle after 100 years of development, there have been many mature cases for reference, some large bearing manufacturer will also provide some design ideas, and the rapid development of the domestic manufacturing industry for sophisticated processing provides a convenient, so design of the spindle is guaranteed, processing also is no longer a bottleneck, if the assembly of scientific and reasonable analysis and thus the development of the corresponding assembly process, then the future will certainly be able to build a spindle system of high accuracy, high rigidity, long service life. 


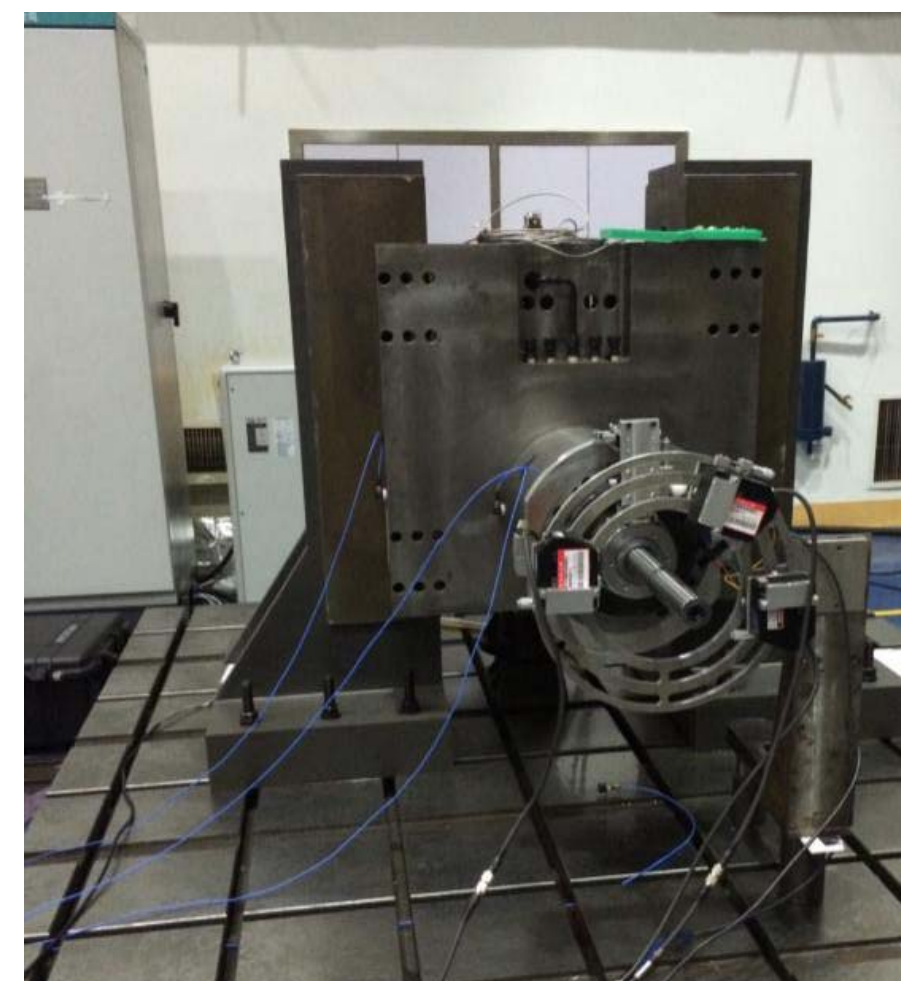

Figure6:free running experiment of spindle system components

\section{Summary}

According to the assembly process, we have assembled a precision spindle unit of the machine tool manufacturing enterprise, which has been tested on the spot, and the quality of the spindle assembly has been improved.

\section{Referance}

[1] Guan Guoqi: The spindle assembly process design of a high precision CNC lathe, J.Manufacturing technology and machine tools.1(2012), p. 45-47

[2] Zhang Xiaodong, Huang Yuming \& Li Lin, in: Analysis and formulation of assembly process of spindle unit of NC lathe, J.Mechanical design and manufacturing (2011)

[3] Lei Lingfei \& Yang Chuanqi, Research on spindle assembly process of NC lathe, J.Process and detection.8(2014), p. 106-110

[4] Niu Ce, Spindle assembly process for heavy duty horizontal lathe, J.Modern machinery.4(2013), p. 17-19 